\title{
Article \\ Fabrication of Eco-Friendly Graphene Nanoplatelet Electrode for Electropolishing and Its Properties
}

\author{
Junyoung Jeong ${ }^{1,2} \oplus$, Wanjun Yoon ${ }^{3}$, Bongjin Chung ${ }^{1,2}$, Giyoung Jeon ${ }^{1,2}$ and Seongwoo Ryu ${ }^{1,2, *}$ \\ 1 Department of Materials Science and Engineering, The University of Suwon, 17, Wauan-gil, Bongdam-eup, \\ Hwaseong-si, Gyeonggi-do 18323, Korea; 20113004@suwon.ac.kr (J.J.); 20113001@suwon.ac.kr (B.C.); \\ urmyalice@suwon.ac.kr (G.J.) \\ 2 Center for Advanced Material Analysis, The University of Suwon, 17, Wanan-gil, Bongdam-eup, \\ Hwaseong-si, Gyeonggi-do 18323, Korea \\ 3 CS Innovation, 26-16, Maebawi-ro, Ujeong-eup, Hwaseong-si, Gyeonggi-do 18559, Korea; \\ ywj1212@suwon.ac.kr \\ * Correspondence: ryu@suwon.ac.kr; Tel.: +82-010-7367-0131
}

check for updates

Citation: Jeong, J.; Yoon, W.; Chung, B.; Jeon, G.; Ryu, S. Fabrication of Eco-Friendly Graphene Nanoplatelet Electrode for Electropolishing and Its Properties. Appl. Sci. 2021, 11, 3224. https://doi.org/10.3390/ app11073224

Academic Editor: Petr Korusenko

Received: 18 February 2021

Accepted: 1 April 2021

Published: 3 April 2021

Publisher's Note: MDPI stays neutral with regard to jurisdictional claims in published maps and institutional affiliations.

Copyright: (c) 2021 by the authors. Licensee MDPI, Basel, Switzerland. This article is an open access article distributed under the terms and conditions of the Creative Commons Attribution (CC BY) license (https:// creativecommons.org/licenses/by/ $4.0 /)$.
Featured Application: Electropolishing electrode, electroplating electrode, lithium-ion battery electrode.

Abstract: Electropolishing is one of the most widely applied metal polishing techniques for passivating and deburring metal parts. Copper is often used as cathode electrode for electropolishing due to its low electrical resistance and low flow values. However, during the electropolishing process, elution of the cathode electrode caused by the electrolyte and remaining oxygen gas also causes critical water pollution and inhibits electropolishing efficiency. Therefore, to achieve an efficient and eco-friendly electropolishing process, development of a highly corrosion resistive and conductive electrode is necessary. We developed a highly oriented graphene nanoplatelet (GNP) electrode that minimizes water pollution in the electropolishing process. We functionalized GNP by a one-step mass-productive ball-milling process and non-covalent melamine functionalization. Melamine is an effective amphiphilic molecule that enhances dispersibility and nematic liquid crystal phase transformation of GNP. The functionalization mechanism and the material interaction were confirmed by Raman spectroscopy after high-speed shear printing. After the electropolishing process by melamine-functionalized GNP electrodes, 304 stainless steel samples were noticeably polished as copper electrodes and elution of carbon was over 50 times less than was the case when using copper electrodes. This electropolishing performance of a highly oriented GNP electrode indicates that melamine-functionalized GNP has great potential for eco-friendly electropolishing applications.

Keywords: graphene; electrode; functionalization; electropolishing; eco-friendly

\section{Introduction}

Electropolishing is one of the most widely applied metal polishing processes, used to passivate and deburr metal parts. Materials to be polished are located as anodes, and counterelectrodes such as $\mathrm{Cu}, \mathrm{Pb}$, and Fe are located as cathodes. A direct electric current (DC) passes through the positive terminal (anode) to the electrolyte and the negative terminal (cathode). Electropolishing is the reverse process of electroplating, in which electric current passes from the anode to cathode, resulting in oxidation of the material surface. The main purposes of the electropolishing process are the removal of impurities on the material surface, establishment of uniform surface roughness, and selective control of surface element composition ratio. Common electrolytes for electropolishing are concentrated acidic solutions based on sulfuric and phosphoric acid. Therefore, elution of the cathode electrode inevitably occurs under this electropolishing process environment. 
Elution from cathode electrodes, such as high concentration $\mathrm{Cu}^{2+}$, is toxic and affects the metabolic processes of marine organisms. Although, naturally, the marine environment contains low concentrations of $\mathrm{Cu}^{2+}$, a concentration of $\mathrm{Cu}^{2+}>0.08 \mu \mathrm{M}$ very negatively affects the completion of different life stages of brown macroalgae. $\mathrm{Cu}^{2+}$ usually forms inorganic and organic complexes with ligands such as thiols and humic substances [1]. Often, the production of high concentration $\mathrm{Cu}^{2+}$ with organic complexes can counteract critical toxic effects to humans and related organisms, including photosynthetic organisms [2]. Moreover, accumulated $\mathrm{Cu}$ in polluted plants can be horizontally transported to other plants directly in soil via connected stolons [3]. Therefore, a highly conductive graphene-based carbon material could be an alternative for cathode electrodes. Graphene has excellent chemical resistance in acidic environments, with high levels of electrical conductivity, mechanical strength, surface area, and flexibility [4,5]. Moreover, graphene with $\pi-\pi$-interacted functional molecules provides homogenous dispersion of graphene which enable solution-based process for conductive electrode applications [6,7].

Herein, we demonstrated an eco-friendly GNP electrode for electropolishing by noncovalently melamine-functionalized GNP electrodes. These functionalized GNP electrodes were fabricated from highly oriented liquid crystals and shear-induced alignment. The electropolishing and elution properties of the GNP electrodes were compared with those of conventional $\mathrm{Cu}$ electrodes. The surface morphologies and compositions of the polished 304 stainless steels were studied to assess the electropolishing quality of GNP electrodes.

\section{Materials and Methods}

\subsection{Materials}

We purchased melamine (Sigma Aldrich, St. Louis, MO, USA), graphene nanoplatelets (GNP) (XG Science, grade M-5, St. Louis, MO, USA), N,N-dimethylformamide (DMF) (Fisher Scientific Co. L.L.C., Pittsburgh, PA, USA), Cu electrode (POSCO, Gyeongsangbukdo, Korea), sulfuric acid (Samchun, Seoul, Korea, 95\%), phosphoric acid (Junsei, Tokyo, Japan, 85\%), and 304 stainless steel (POSCO, Gyeongsangbuk-do, Korea).

\subsection{Synthesis of Melamine-GNP (M-GNP) and Film Fabrication}

Melamine-GNPs (M-GNPs) were fabricated by the following method. Melamine and GNP were mixed with $200 \mathrm{~mL}$ DMF in a beaker. The mixture was sonicated for $1 \mathrm{~h}$. The mixture and stainless balls were poured into a polypropylene bottle and mixed for $24 \mathrm{~h}$ at $50 \mathrm{rpm}$ with a ball milling machine. The ball milling process (SH-BALL700-2, Samheung Energy, Sejong, Korea) product was vacuum filtrated through a polytetrafluoroethylene (PTFE) (Hyundai Micro Co., LTD., Seoul, Korea) membrane. The resultant M-GNP was dried in a vacuum oven at $70{ }^{\circ} \mathrm{C}$ for $24 \mathrm{~h}$. DI water was added to the dried M-GNP powder. The mixture was dispersed using a vortex mixer for $10 \mathrm{~min}$. The nematic phase of the mixture had a concentration of $250 \mathrm{mg} / \mathrm{mL}$. The mixture was poured onto a flat PTFE sheet and spread by high-speed extrusion using a doctor blade (BEVS1811/1 Automatic Film Applicator, BEVS, Guangzhou, China) at a speed of $50 \mathrm{~mm} / \mathrm{s}$. After this, the film was dried in a vacuum oven at $70{ }^{\circ} \mathrm{C}$ for $24 \mathrm{~h}$.

\subsection{Characterization}

\subsubsection{M-GNP Film Characterization}

The chemical composition of the M-GNP was analyzed by X-ray Photoelectron Spectroscopy (XPS) (K-alpha plus, Thermo Fisher Scientific, Waltham, MA, USA) and Confocal Micro-Raman (FEX, NOST, Gyeonggi, Korea) Spectroscopy. The microstructure M-GNP and pristine GNP were analyzed by Scanning Electron Microscopy (SEM) (APREO, FEI, Hillsboro, OR, USA). The mechanical strength of the GNP film was measured using a micro-force testing machine (Micro Tester 8848; Instron, Seoul, Korea). The conductivity of the M-GNP film was measured using a 4-point probe (CMT-SR1000N, Advanced Instrument Technology, Cumming, GA, USA). 


\subsubsection{Electropolishing Characterization}

The roughness of each electrode was measured using a surface roughness tester (Bruker Korea Co., LTD., DektakXT, Seoul, Korea). The chemical composition of the GNP electrode, copper electrode, and pristine stainless steel was determined by X-ray Photoelectron Spectroscopy (XPS) (K-alpha plus, Thermo Fisher Scientific, Waltham, MA, USA). For comparison of the $\mathrm{Cr} / \mathrm{Fe}$ ratios, each electrode was analyzed by Auger Electron Spectroscopy (AES) (PHI-700, ULVAC-PHI, Kanagawa, Japan). Analysis to determine the component content eluted from each electrode was performed by ICP (Thermo Fisher Scientific, iCAP 7000, Waltham, MA, USA) and TOC (Shimadzu, Total Organic Carbon Analyzer TOC-L, Kyoto, Japan). For the electropolishing process, 304 stainless steel $(10 \mathrm{~cm}$ $\times 10 \mathrm{~cm}$ ) was connected to the positive electrode (anode). The negative electrode (cathode) was connected to a copper or GNP electrode. Then, a current density of 20 ASD was induced at a temperature of $45^{\circ} \mathrm{C}$ for $10 \mathrm{~min}$ [8-10].

\section{Results and Discussion}

GNP was noncovalently functionalized by melamine to form highly oriented liquid crystals. We used a one-step ball milling process for the melamine functionalization process. The ball milling process for graphene functionalization has advantages on mass production for defect-free graphenes [11]. The functionalization of GNPs was verified by spectroscopic analysis. The XPS and Raman spectra of the functionalized GNP are presented in Figure 1. Peaks corresponding to $C$ and $O$ elements were observed for pristine GNPs, and after melamine functionalization, additional $\mathrm{N}$ element was observed in a survey scan (Figure 1a). The C1s peak region in the XPS spectra of the GNPs (Figure 1b,c) was deconvoluted into five peaks at about 284.6, 285.2, 286.2, 286.58, and $289.08 \mathrm{eV}$, which corresponded to $\mathrm{C}=\mathrm{C}, \mathrm{C}-\mathrm{C}, \mathrm{C}-\mathrm{O}, \mathrm{C}-\mathrm{N}$, and $\pi-\pi^{*}$ shake-up entities, respectively. The peak at $284.6 \mathrm{eV}$ was attributed to the $\mathrm{sp}^{2}$ graphitic structure with a $\pi-\pi^{*}$ transition peak at $289.08 \mathrm{eV}$, indicating interaction between GNPs. The peak at $286.2 \mathrm{eV}$ was attributed to defects in the GNPs (Figure 1b). After non-covalent functionalization, an additional peak at $286.58 \mathrm{eV}$ was exhibited, corresponding to the $\mathrm{C}-\mathrm{N}$ bonds of melamine (Figure 1c) [12,13]. The Raman spectra of pristine GNPs and M-GNP showed D-, G-, and 2D bands at 1345, 1574 , and $\sim 2700 \mathrm{~cm}^{-1}$ (Figure 1d), respectively. GNP and M-GNP had similar $\mathrm{I}_{\mathrm{D}} / \mathrm{I}_{\mathrm{G}}$ ratios because noncovalent processes do not affect the intrinsic properties of GNP. The $I_{D} / I_{G}$ ratio of the pristine GNP was 0.906 ; that of M-GNP was 0.95 . However, a significant shift and shape difference in the 2D band was observed between GNP and M-GNP. Compared with that of pristine GNPs $\left(2688 \mathrm{~cm}^{1}\right)$, the 2D band of the M-GNPs was upshifted to $2690 \mathrm{~cm}^{-1}$ [14]. The increase in the number of $\pi-\pi$ interactions among the hexagonal rings of graphenes split the $\pi$ and $\pi^{*}$ bands due to the frequency of the scattering phonons, which is determined by the double-resonance condition [15]. As a result, the increased number of $\pi-\pi$ interactions resulted in an upshift of the 2D bands. Therefore, the upshifted $2 \mathrm{D}$ band of M-GNP indicates that melamine molecules interacted with the GNP surface via $\pi-\pi$ interactions [11].

To observe the liquid crystal phase transition of M-GNP from isotropic to nematic, a $20 \mathrm{mg} / \mathrm{mL}$ M-GNP suspension was observed by polarized optical microscopy (POM) (Figure 2a). The birefringence domains were observed at $20 \mathrm{mg} / \mathrm{mL}$ of M-GNP, which is a common characteristic of lyotropic liquid crystal materials. Then, these nematic-phase gels were spread on a PTFE substrate with direct doctor blades printing. By applying shear forces to nematic-phase gels, M-GNP particles created highly aligned parallel structures of pre-standing films. The M-GNP film was fabricated into a rectangular shape with dimensions of $5 \mathrm{~cm} \times 2 \mathrm{~cm}$; the thickness of the M-GNP film was $15.59 \pm 0.493 \mu \mathrm{m}$ $(n=6)$ (Figure 2b) [16]. We observed that M-GNP was highly oriented in the lateral direction, and micrometer-scale voids and defects disappeared. This highly oriented structure offers a larger sized graphene domain and induces both high load transfer and modulus properties. Micro-voids and defects often cause stress concentration during deformation of the films. Therefore, the lateral orientation of the graphene particle is one 
of the key elements enhancing the mechanical and electrical properties of the films [17]. Within this highly oriented structure, the M-GNP film exhibited both higher modulus $(4.2 \pm 0.71 \mathrm{GPa}, \mathrm{n}=6)$ and 161 higher strength $(70.5 \pm 10.8 \mathrm{MPa}, \mathrm{n}=6)$ than those values of vacuum-filtered GNP films (Figure 2c). Ideal GNP has a high mobility beyond $200,000 \mathrm{~cm}^{2} /$ Vs, but M-GNP films were fabricated using multiple lateral crystals, for which the electrical conductivity of the film depends on the tunneling model [18]. With this highly oriented structure, the effective contact area was maximized compared to the case of vacuum-filtered GNP films ( $89.54 \pm 17.49 \mathrm{~S} / \mathrm{cm}, \mathrm{n}=9$ ); the liquid crystal-based M-GNP film exhibited a $1150 \%$ enhanced electrical conductivity $(1032.89 \pm 26.41 \mathrm{~S} / \mathrm{cm}, \mathrm{n}=6)$ (Figure 2d) [19]. Compared to M-GNP films, the GNP film is fragile and has less than $1 / 10$ of the electrical conductivity that GNP films could be directly applied as cathode electrodes for electropolishing.
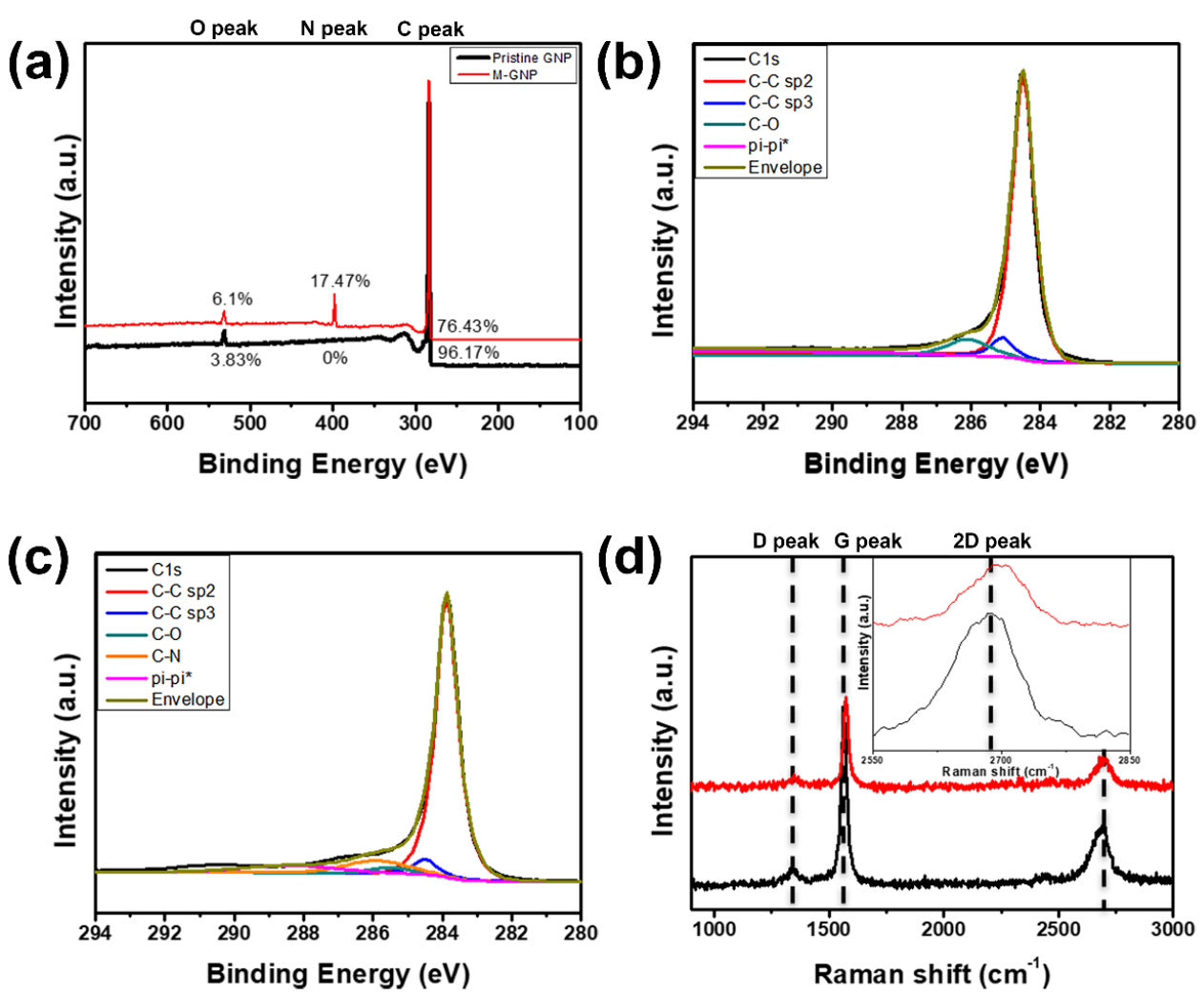

Figure 1. X-ray Photoelectron Spectroscopy (XPS) of GNP and M-GNP. (a) Survey and (b) high resolution C1s peak regions of GNP and (c) M-GNP. (d) The Raman spectroscopy of GNP and M-GNP.

The M-GNP film was directly applied as cathode electrode for electropolishing of 304 stainless steel through an electrolyte (sulfuric acid: phosphoric acid $=2: 8$ ) [20-22] in an electrolytic cell (temperature: $45^{\circ} \mathrm{C}$, current density: 20 ASD, sample size: $10 \mathrm{~cm} \times 10 \mathrm{~cm}$, experiment time: $10 \mathrm{~min}$ ). Figure 3 provides a comparison of 304 stainless steel electropolished by the conventional $\mathrm{Cu}$ electrode and by the M-GNP electrode. Before the electropolishing process, the microstructure of the 304 stainless steel specimen showed clear grain boundaries with surface roughness $\left(\mathrm{R}_{\mathrm{a}}^{0}\right)$ of $5.25 \pm 1.15 \mu \mathrm{m}(\mathrm{n}=5)$. However, after the electropolishing process, most of the grain boundaries faded out, leading to low surface roughness $\left(R_{a}^{f}\right)$ of both the $C u(0.62 \pm 0.12) \mu \mathrm{m}(n=5)$, Figure $\left.3 b\right)$ and M-GNP $(0.67 \pm 1.8) \mu \mathrm{m}(\mathrm{n}=5)$, Figure $3 \mathrm{c})$ electrodes $[23,24]$. The polishing percentage was calculated in terms of decreasing percentages of the arithmetic mean roughness value; both $\mathrm{Cu}$ $(88 \%)$ and M-GNP $(86 \%)$ electrodes had polishing values of over $85 \%$. The XPS spectra of the binding energy regions of Fe2p (714.68 eV), Ni2p (858.1 eV), and Cr2p (580.32 eV) electrons were obtained from the polished 304 stainless steel $[25,26]$. The composition and thickness of the surface were calculated using theoretical auger depth profiling analy- 
sis [27]. At the surface and in the internal areas, the pristine 304 stainless steel exhibited a composition of Fe $26.56 \%$, Ni $7.36 \%$, and $\mathrm{Cr} 2.37 \%$ (Figure 3d). After electropolishing with $\mathrm{Cu}$ electrodes, surface $\mathrm{Fe}$ decreased to $12.65 \%$ and surface $\mathrm{Cr}$ increased to $16.65 \%$ (Figure 3e). After electropolishing with M-GNP electrodes, surface Fe decreased to $17.64 \%$ and $\mathrm{Cr}$ increased to $16.28 \%$ (Figure 3f). The intent of passivation of stainless steel is to remove free iron or other foreign matter from the surface and to create a Cr-rich surface that is resistant to corrosion [28,29]. Therefore, as well as surface polishing, M-GNP showed similar levels of surface passivation of 304 stainless steels.

(a)

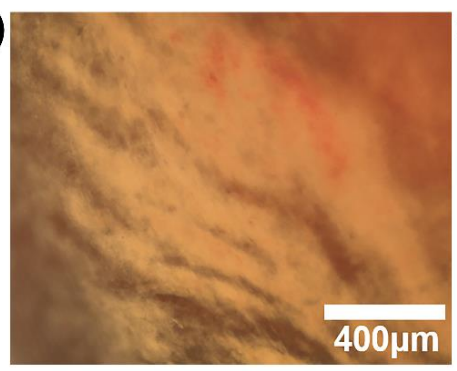

(c)

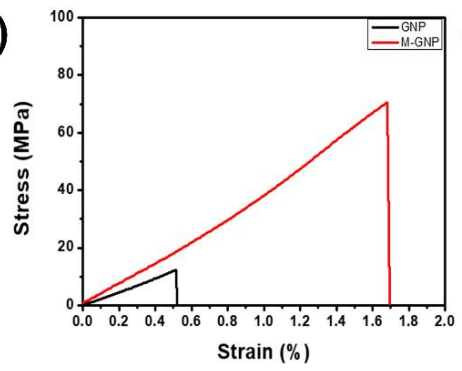

(b)

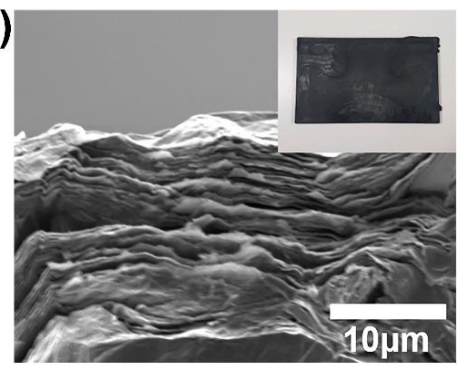

(d)

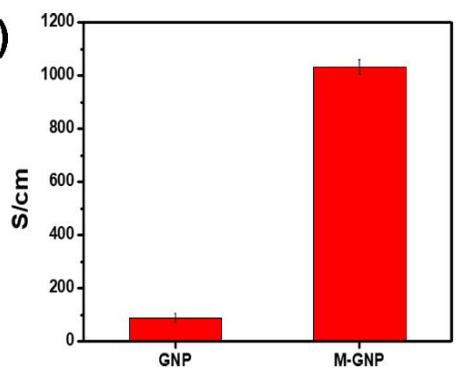

Figure 2. Microstructure and properties of M-GNP electrodes. (a) Polarized optical microscopy (POM) image of $20 \mathrm{mg} / \mathrm{mL}$ of M-GNP. (b) SEM image and photograph of M-GNP electrode $(5 \mathrm{~cm} \times 2 \mathrm{~cm})$. (c) Tensile properties of GNP and M-GNP and (d) their electrical conductivity.

(a)

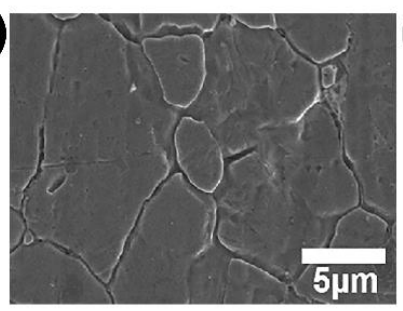

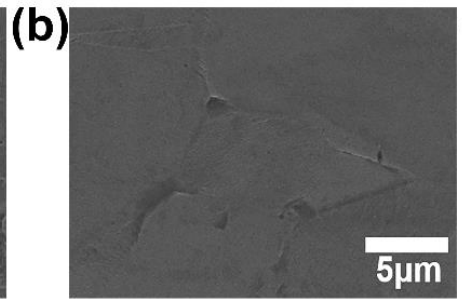
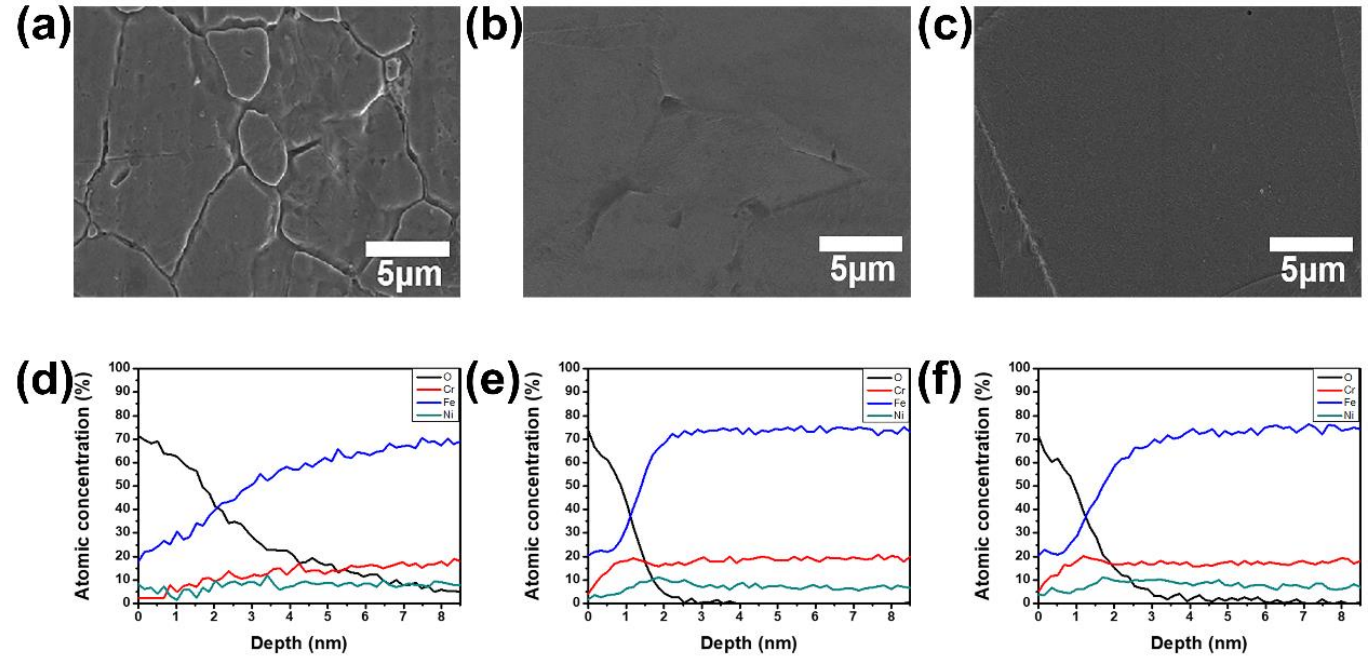

Figure 3. Microstructure and chemical composition of 304 stainless steel after electropolishing. (a) SEM image of pristine 304 stainless steel and stainless steel after (b) electropolishing at the Cu electrode and (c) M-GNP electrode. Auger depth profiling analysis of (d) pristine 304 stainless steel and stainless steel after (e) electropolishing at the Cu electrode and (f) M-GNP electrode. 
After 400 cycles of electropolishing, elution of cathode electrode was observed by ICP analysis. Figure 4 shows the amount of eluted $\mathrm{Cu}$ electrodes and M-GNP electrodes. After 100 cycles of electropolishing, the $\mathrm{Cu}$ electrode eluted by 14 ppm (Figure 4a). Until 400 cycles, the eluted $\mathrm{Cu}$ constantly increased as the electropolishing process continued. After 400 cycles, eluted $\mathrm{Cu}$ was over $41 \mathrm{ppm}$. This degradation of the electrode can be directly observed in the SEM image (Figure $4 \mathrm{~b}$ ). Compared to the pristine $\mathrm{Cu}$ electrodes, few-micrometer-sized pores were observed because of degradation of $\mathrm{Cu}$ [26]. On the other hand, the elution of the M-GNP electrode was under $0.8 \mathrm{ppm}$ for the entire 400 cycles, and this elution of M-GNP is 50 times less than those of the $\mathrm{Cu}$ electrodes (Figure 4c). The microstructure of the M-GNP electrodes remained similar to the pristine state (Figure $4 \mathrm{~d}$ ). This result indicates that M-GNP electrodes have enhanced durability compared to that of $\mathrm{Cu}$ electrodes and could minimize water pollution during the electropolishing process.

(a)

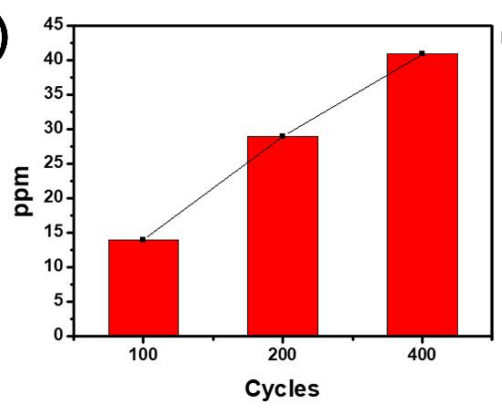

(c)

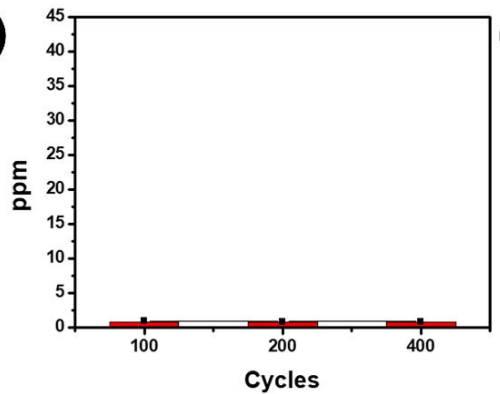

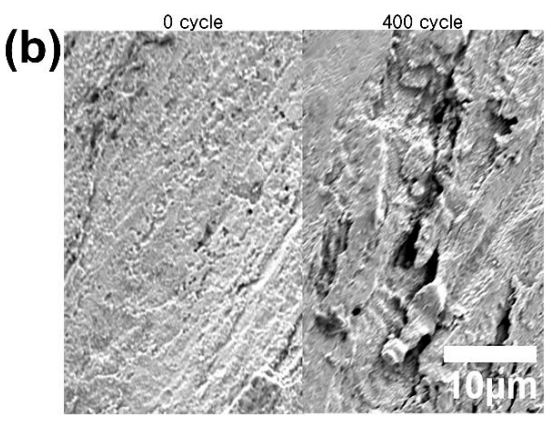

0 cycle

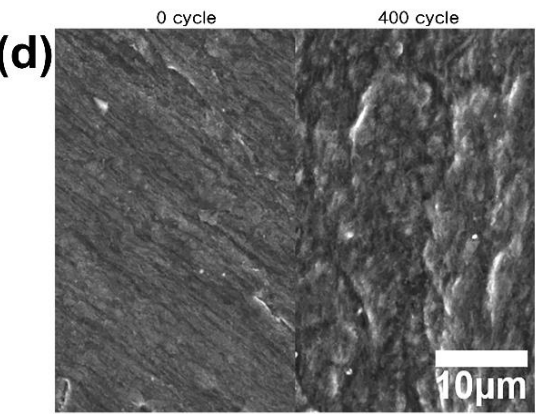

Figure 4. Cyclic elution of $\mathrm{Cu}$ and M-GNP electrodes. (a) Cu components of electrolytes after 400 cycles of $\mathrm{Cu}$ electrode electropolishing. (b) SEM image of $\mathrm{Cu}$ electrodes after 400 cycle of electropolishing. (c) C components of electrolytes after 400 cycles of M-GNP electrode electropolishing. (d) SEM image of M-GNP electrodes after 400 cycles of electropolishing.

\section{Conclusions}

In summary, eco-friendly GNP electrodes for the electropolishing process were developed using melamine-functionalized liquid crystal GNP-based films. Highly oriented conductive M-GNP electrodes were directly fabricated by nematic liquid crystal phase transformation. The polishing performance of the M-GNPs, as indicated by the arithmetic mean roughness value (over $85 \%$ ), and the surface passivation of the stainless steel were comparable to those of conventional Cu electrodes. Furthermore, after 400 cycles of electropolishing, elution of M-GNP was over 50 times less than is the case for conventional $\mathrm{Cu}$ electrodes. This electropolishing performance of M-GNP electrodes indicates that M-GNP has great potential to reduce critical water pollution as a durable and eco-friendly electrode electropolishing process.

Author Contributions: Conceptualization, S.R.; Data curation, B.C. and G.J.; Formal analysis, J.J. and W.Y.; Investigation, S.R.; Methodology, J.J. and W.Y.; Writing—original draft, J.J.; Writing—review \& editing, S.R. All authors have read and agreed to the published version of the manuscript. 
Funding: This research was funded by a Grant (20CTAP-C157479-01) from Technology Advancement Research Program funded by the Ministry of Land, Infrastructure and Transport of the Korean Government and the Technology Development Program (S2894402) funded by the Ministry of SMEs and Startups (MSS, Korea).

Institutional Review Board Statement: Not applicable.

Informed Consent Statement: Not applicable.

Acknowledgments: The research was supported by a Grant (20CTAP-C157479-01) from Technology Advancement Research Program funded by the Ministry of Land, Infrastructure and Transport of the Korean Government. This work was supported by the Technology Development Program (S2894402) funded by the Ministry of SMEs and Startups (MSS, Korea).

Conflicts of Interest: The authors declare no conflict of interest.

\section{References}

1. Leal, P.P.; Hurd, C.L.; Sander, S.G.; Armstrong, E.; Fernández, P.A.; Suhrhoff, T.J.; Roleda, M.Y. Copper pollution exacerbates the effects of ocean acidification and warming on kelp microscopic early life stages. Sci. Rep. 2018, 8, 14763. [CrossRef] [PubMed]

2. Tchounwou, P.B.; Yedjou, C.G.; Patlolla, A.K.; Sutton, D.J. Heavy Metal Toxicity and the Environment. Exp. Suppl. 2012. [CrossRef]

3. $\mathrm{Xu}, \mathrm{L} . ; \mathrm{Zhou}, \mathrm{Z}$.-F. Effects of $\mathrm{Cu}$ Pollution on the Expansion of an Amphibious Clonal Herb in Aquatic-Terrestrial Ecotones. PLoS ONE 2016, 11, e0164361. [CrossRef] [PubMed]

4. Topsakal, M.; Şahin, H.; Ciraci, S. Graphene coatings: An efficient protection from oxidation. Phys. Rev. B 2012, 85, 155445. [CrossRef]

5. Su, Y.; Kravets, V.G.; Wong, S.L.; Waters, J.; Geim, A.K.; Nair, R.R. Impermeable barrier films and protective coatings based on reduced graphene oxide. Nat. Commun. 2014, 5, 4843. [CrossRef]

6. Dai, L. Functionalization of Graphene for Efficient Energy Conversion and Storage. Acc. Chem. Res. 2013, 46, 31-42. [CrossRef]

7. Zhang, L.L.; Zhao, X.S. Carbon-based materials as supercapacitor electrodes. Chem. Soc. Rev. 2009, 38, 2520-2531. [CrossRef]

8. Bhuyan, A.; Gregory, B.; Lei, H.; Yee, S.Y.; Gianchandani, Y.B. Pulse and DC Electropolishing of Stainless Steel for Stents and Other Devices. In Proceedings of the IEEE Sensors 2005, Irvine, CA, USA, 30 October-3 November 2005. [CrossRef]

9. Ponto, L.; Datta, M.; Landolt, D. Electropolishing of iron-chromium alloys in phosphoric acid-sulphuric acid electrolytes. Surf. Coat. Technol. 1987, 30, 265-276. [CrossRef]

10. Faust, C.L. Surface Preparation by Electropolishing. J. Electrochem. Soc. 1949, 95. [CrossRef]

11. Kim, J.; Cha, J.; Jun, G.H.; Yoo, S.C.; Ryu, S.; Hong, S.H. Fabrication of Graphene Nanoplatelet/Epoxy Nanocomposites for Lightweight and High-Strength Structural Applications. Part. Part. Syst. Charact. 2018, 35, 1700412. [CrossRef]

12. Teng, C.-C.; Ma, C.-C.M.; Lu, C.-H.; Yang, S.-Y.; Lee, S.-H.; Hsiao, M.-C.; Yen, M.-Y.; Chiou, K.-C.; Lee, T.-M. Thermal conductivity and structure of non-covalent functionalized graphene/epoxy composites. Carbon 2011, 49, 5107-5116. [CrossRef]

13. Choi, E.-Y.; Han, T.H.; Hong, J.; Kim, J.E.; Lee, S.H.; Kim, H.W.; Kim, S.O. Noncovalent functionalization of graphene with end-functional polymers. J. Mater. Chem. 2010, 20, 1907-1912. [CrossRef]

14. Cha, J.; Jun, G.H.; Park, J.K.; Kim, J.C.; Ryu, H.J.; Hong, S.H. Improvement of modulus, strength and fracture toughness of CNT/Epoxy nanocomposites through the functionalization of carbon nanotubes. Compos. Part B Eng. 2017, 129, 169-179. [CrossRef]

15. Ferrari, A.C.; Meyer, J.C.; Scardaci, V.; Casiraghi, C.; Lazzeri, M.; Mauri, F.; Piscanec, S.; Jiang, D.; Novoselov, K.S.; Roth, S.; et al. Raman spectrum of graphene and graphene layers. Phys. Rev. Lett. 2006, 97, 1-4. [CrossRef] [PubMed]

16. Cha, J.; Jin, S.; Shim, J.H.; Park, C.S.; Ryu, H.J.; Hong, S.H. Functionalization of carbon nanotubes for fabrication of CNT/epoxy nanocomposites. Mater. Des. 2016, 95, 1-8. [CrossRef]

17. Ren, P.-G.; Yan, D.-X.; Chen, T.; Zeng, B.-Q.; Li, Z.-M. Improved properties of highly oriented graphene/polymer nanocomposites. J. Appl. Polym. Sci. 2011, 121, 3167-3174. [CrossRef]

18. Payandehpeyman, J.; Mazaheri, M.; Khamehchi, M. Prediction of electrical conductivity of polymer-graphene nanocomposites by developing an analytical model considering interphase, tunneling and geometry effects. Compos. Commun. 2020, 21, 100364. [CrossRef]

19. Chen, H.; Müller, M.B.; Gilmore, K.J.; Wallace, G.G.; Li, D. Mechanically Strong, Electrically Conductive, and Biocompatible Graphene Paper. Adv. Mater. 2008, 20, 3557-3561. [CrossRef]

20. Lee, E.-S. Machining Characteristics of the Electropolishing of Stainless Steel (STS316L). Int. J. Adv. Manuf. Technol. 2000, 16, 591-599. [CrossRef]

21. Rohly, K.; Istephanous, N.; Belu, A.; Untereker, D.; Coscio, M.; Heffelfinger, J.; Thomas, R.; Allen, J.; Francis, R.; Robinson, A.; et al. Effect of Time, Temperature, and Solution Composition on the Passivation of 316L Stainless Steel for Biomedical Applications. Mater. Sci. Forum 2003, 426-432, 3017-3022. [CrossRef]

22. Nazneen, F.; Galvin, P.; Arrigan, D.W.M.; Thompson, M.; Benvenuto, P.; Herzog, G. Electropolishing of medical-grade stainless steel in preparation for surface nano-texturing. J. Solid State Electrochem. 2012, 16, 1389-1397. [CrossRef] 
23. Lin, C.-C.; Hu, C.-C. Electropolishing of 304 stainless steel: Surface roughness control using experimental design strategies and a summarized electropolishing model. Electrochim. Acta. 2008, 53, 3356-3363. [CrossRef]

24. Awad, A.M.; Ghany, N.A.A.; Dahy, T.M. Removal of tarnishing and roughness of copper surface by electropolishing treatment. Appl. Surf. Sci. 2010, 256, 4370-4375. [CrossRef]

25. Haïdopoulos, M.; Turgeon, S.; Sarra-Bournet, C.; Laroche, G.; Mantovani, D. Development of an optimized electrochemical process for subsequent coating of 316 stainless steel for stent applications. J. Mater. Sci. Mater. Med. 2006, 17, 647-657. [CrossRef] [PubMed]

26. Stefanov, P.; Stoychev, D.; Stoycheva, M.; Gonzalez-Elipe, A.R.; Marinova, T. XPS, SEM and TEM characterization of stainless-steel 316L surfaces after electrochemical etching and oxidizing. Surf. Interface Anal. 1999, 28, 106-110. [CrossRef]

27. Wang, J.; Tarapata, C.J.; Fitz, M.J. Electro-polishing fixture and electrolyte solution for polishing stents and method. U.S. Patent No. 6,375,826, 23 April 2002.

28. Lee, S.-J.; Lai, J.-J. The effects of electropolishing (EP) process parameters on corrosion resistance of 316L stainless steel. J. Mater. Process. Technol. 2003, 140, 206-210. [CrossRef]

29. Thierry, B.; Tabrizian, M.; Trepanier, C.; Savadogo, O.; Yahia, L. Effect of surface treatment and sterilization processes on the corrosion behavior of NiTi shape memory alloy. J. Biomed. Mater. Res. 2000, 51, 685-693. [CrossRef] 